\title{
SOSIALISASI PENCEGAHAN KASUS STROKE PADA LANJUT USIA DI DESA HAMPARAN PERAK KECAMATAN
}

\author{
SULAIMAN M.KM ${ }^{1)}$, ANGGRIANI Sst,Ft, M.KM ${ }^{2)}$ \\ Stikes Siti Hajar Medan \\ man_fisioterapi@yahoo.co.id ${ }^{1)}$ \\ anggri_pru@yahoo.co.id ${ }^{2}$ )
}

\begin{abstract}
ABSTRAK
Stroke merupakan masalah kesehatan yang paling utama bagi Indonesia pada saat ini. Stroke semakin menjadi masalah serius yang dihadapi hampir diseluruh dunia. Hal tersebut dikarenakan serangan stroke dapat menyerang secara mendadak dan dapat mengakibatkan kematian, kecacatan fisik dan mental. Stroke merupakan penyakit defisit neurologis akut yang disebabkan oleh gangguan pembuluh darah otak, terjadi secara mendadak dan menimbulkan gejala atau tanda yang sesuai dengan daerah otak yang terganggu. Gangguan stroke banyak terjadi pada lanjut usia. Kasus ini terjadi di Desa Hamparan Sumatera Utara. Metode yang digunakan dalam pengabdian masyarakat ini menggunakan metode penyuluhan, dan penanganan lansia langsung dengan meberikan tindakan berupa pemeriksaan tekanan darah, massage, dan pemeberian sinar infared yang ditujukan kepada lanjut usia dan kelompok posyandu . Tujuan Pengabdian Masyarakat ini adalah memberikan peningakatan kesehatan keapada lanjut usia di Desa Hamparan Perak, terhindar dari terkena serangan stroke dan mengerti atas bahaya stroke. Hasil dari Pengabdian Kepada Masyarakat ini terjadi peningkatan kesadaran lanjut usia dan keluarga lanjut usia dalam memeriksakan kesehatannya setiap bulannya ke posyandu, Kesimpulan dari pengabdian ini adalah Pemberian sinar infra red untuk lansia yang mengalami gejala stroke dan stroke serta gangguan fisik lainnya sangat efektif karena manfaatnya langsung dapat dirasakan oleh lansia
\end{abstract}

Kata Kunci : Stroke, Lanjut Usia

\begin{abstract}
Stroke is the most important health problem for Indonesia at this time. Stroke is increasingly becoming a serious problem facing almost all over the world. This is because a stroke can strike suddenly and can result in death, physical and mental disability. Stroke is a disease of acute neurological deficits caused by cerebral vascular disorders, occurring suddenly and causing symptoms or signs that correspond to the affected brain area. Stroke disorders occur mostly in the elderly. This case occurred in the village of Hamparan Perak, North Sumatera.The method used in this community service uses counseling methods, and direct elderly handling by giving actions in the form of blood pressure checks, massage, and infared, aimed at elderly and integrated service post groups. The aim of this Community Service is to provide health improvement for the elderly in the village of Hamparan Perak, avoiding stroke and understanding the dangers of stroke. The results of Community Service are an increase in awareness of elderly and elderly families in checking their health every month to the integrated service post. Conclusion, this dedication is the provision of infrared rays for the elderly who experience symptoms of stroke and stroke and other physical disorders are very effective because the benefits can be directly felt by the elderly.
\end{abstract}

Keywords: Stroke, Elderly

1. PENDAHULUAN

Desa Hamparan Perak

Kecamatan Hamparan Perak

Kabupaten Deli Serdang Provinsi

Sumatera Utara merupakan salah satu desa yang ada di Kecamatan Hamparan Perak. Penduduk Kecamatan Hamparan Perak rata-rata suku melayu sebesar $70 \%$, sisanya terdiri dari suku jawa, tionghoa, karo, batak dan berbagai suku lainnya. Penduduk lanjut usia di Desa Hamparan Perak rata-rata terkena penyakit fisik berupa gangguan stroke. Hal ini yang menjadi beban keluarga jika tidak segera di beri penanganan kesehatan dengan serius. 
Stroke merupakan masalah kesehatan yang utama bagi masyarakat modern saat ini. Dewasa ini, stroke semakin menjadi masalah serius yang dihadapi hampir diseluruh dunia. Hal tersebut dikarenakan serangan stroke yang mendadak dapat mengakibatkan kematian, kecacatan fisik dan mental. Stroke merupakan penyakit defisit neurologis akut yang disebabkan oleh gangguan pembuluh darah otak, terjadi secara mendadak dan menimbulkan gejala atau tanda yang sesuai dengan daerah otak yang terganggu. Klasifikasi stroke dibagi menjadi dua, yaitu pendarahan yang mendadak karena pecahnya pembuluh darah di otak (stroke hemoragik), dan asupan darah ke otak berkurang atau pengumpulan darah atau penyumbatan pembuluh darah (nonhemoragik) (Sutrisno, 2007). Stroke adalah suatu penyakit yang diawali dengan terjadinya serangkaian perubahan dalam otak yang terserang yang apabila tidak ditangani dengan segera berakhir dengan kematian bagian otak tersebut.

Pada Lansia akan terjadi proses menua, di mana proses menua ini merupakan suatu proses menghilangnya kemampuan jaringan secara perlahan-lahan untuk mengganti/memperbaiki diri dan mempertahankan fungsi normalnya sehingga tidak dapat bertahan terhadap infeksi dan memperbaiki kerusakan yang diderita. Perubahanperubahan mengenai sistem muskuloskeletal, saraf, kardiovaskular-respirasi, sistem indra (pengelihatan, pendengaran, pengecap, dan peraba), dan sistem integumen yang akan terjadi pada proses penuaan. Perubahan sistem muskuloskeletal yang terjadi pada lansia yaitu perubahan fungsional otot yang dapat mengakibatkan perubahan bentuk tulang lansia.

Sesuai analisis lapangan dan wawancara langsung kepada kepala Desa Hamparan Perak dan kelompok posyandu sebelum dilakukan pengabdian masyarakat dilakukan bahwa jumlah lansia yang aktif mengecek kesehatannya ke posyandu orang dan rata-rata mengalami gangguan fisik, salah satunya terserang stroke. Hal yang membuat tim pengabdian tertarik untuk melakukan pengabdian di Desa Hamparan Perak Kecamatan Hamparan Perak Kabupaten Deli Serdang.

\section{Permasalahan}

$\begin{array}{ccc}\text { Berdasarkan } & \text { analisis } & \text { dan } \\ \text { wawancara yang } & \text { dilakuan tim }\end{array}$ pengabdian yang dilakukan di Desa Hamparan Perak, terdapat permasalahan yang sangat serius yang dihadapi oleh para lansia, selain gejala stroke yang dialami, namun kasus-kasus penyakit lain juga tak kalah banyaknya yang dialami lansia seperti osteoporosis, peradangan sendi dan lain-lainnya. Dalam hal kegiatan ini sebagai mitra dalam pengabdian ini adalah kelompok posyandu Desa Hamparan Perak dan lanjut usia. Permasalahan tersebut dapat dirincikan sebagai berikut :

1. Lanjut usia rata-rata mengalami stoke yang memang sering dialami oleh lansia. Keluaraga tidak rutin mengecekan kesehatan di posyandu yang leah disegiakan

2. Fasilitas sarana dan prasarana posyandu lansia di Desa Hamparan Perak yang masih kurang memadai untuk memberikan pelayanan 
kesehatan kepada lansia. Ini juga merupakan faktor yang sangat mempengaruhi lansia unutk datang ke posyandu setiap bulannya.

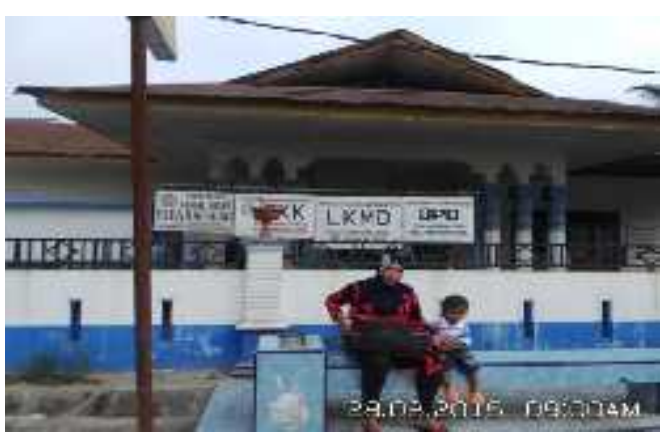

Gambar 1. Lokasi Pengabdian Desa Hamparan Perak

\section{Permasalahan Prioritas}

Setelah melihat permasalahan yang di alami oleh mitra cukup banyak, perlu adanya kesadaran atau tindakan dari masyarakat sendiri. Untuk itu perlunya dilakukan pengbdian ini. Tim Pengabdian melakukan kegiatan dengan mahasiswa tingkat akhir yang telah mempunyai keahlian fisioterapi langsung diterjunkan Desa Hamparan Perak Kecamatan Hamparan Perak Kabupaten Deli Serdang Sumatera Utara untuk memberikan solusi dari permasalahan yang dihadapi di Desa Hamparan Perak. Adapun kegiatan pengabdian ini diprioritaskan pada :

1. Meminimalkan kasus-kasus penyakit gangguan fisik yang dialami oleh para lansia khususnya gejala stroke dan stroke

2. Memberikan penanganan berupa tindakan fisioterapi kepada lanjut usia.

3. Memberikan penyuluhan kesehatan kepada lanjut usia dan kelompok posyandu di Desa Hamparan Perak.

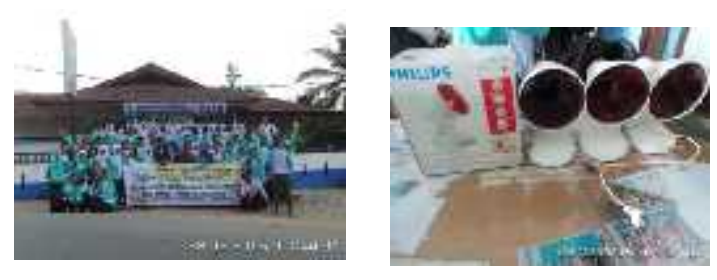

Gambar 2. Tim Pengabdian dan perlatan yang digunakan

\section{METODE PELAKSANAAN}

Metode pelaksanaan dalam penagbdian ini adalah dengan ceramah dan tindakan langsung berupa penanganan fisioterapi. Tim pengabdian yang akan dilakukan sebagai berikut:

1. Melakukan kesepakatan dengan mitra dalam hal ini Posyandu dan Kepala Desa Hamparan. Hal ini sangat penting agar tim dalam melaksanakan mendapat dukungan dan hasilnya bisa sesuai harapan. Dengan demikian tujuan dan harapan dapat direalisasikan dengan baik

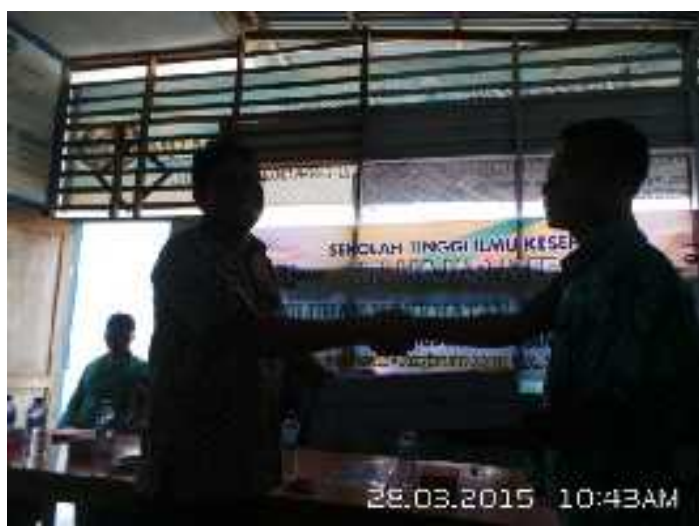

Gambar 3. Melakukan kesepakatan dengan mitra dalam hal ini di wakili oleh Kepala Desa Hamparan Perak 
2. Melakukan analisis lapangan yaitu mengidentifikasi permasalahan yang ada di Desa Hamparan Perak Kecamatan Hamparan Perak. Ini dilakukan agar sebelum melakukan tindakan tim telah mempunyai data yang valid, sehingga perencanaan pengabdian lebih mudah dilaksanakan

3. Melakukan penyuluhan kesehatan terhadap lansia dalam hal ini target pelaksanaannya sebanyak 50 lanjut usia yang mengalami gejala stoke dan stroke dan gangguan fisik lainnya. Hal ini sangat penting dilakukan mengingat para lanjut usia dan keluarga kurang sadar akan pentingnya kesehatan di hari tua. Selain nantinya menjadi beban keluarga dan juga akan menjadi beban masyarakat disekitarnya..
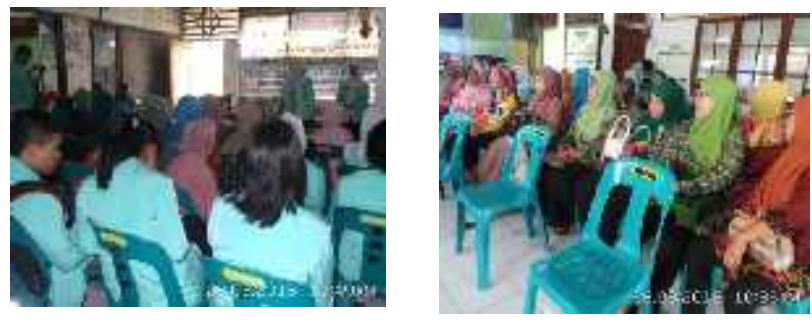

Gambar 4. Penyuluhan kesehatan kepada lanjut usia

4. Metode selanjutnya yaitu melakukan tidakan penanganan fisioterapi pada lanjut usia. Selama ini para lanjut usia belum pernah merasakan tindakan fisioterapi yang tim berikan. Selama ini hanya mendapat penanganan kesehatan dasar saja setiap bulannya yang dilakukan dib alai desa Hamparan Perak.
Tindakan terbeut berupa pemberian sinar infra red, cek gula darah, dan tim juga memberikan senam lansia, dan pemberian manual terapi. Tujuan dari pemberian sinar infra red salah satunya unutk memperlancar aliran darah yang selam ini tersumbat. Hal ini perlu dilakukan minimal 3 kali dalam seminggu. Keluarga juga dapat melakukan penyinaran infra red dirumah unutk menghemat biaya fisioterapi.
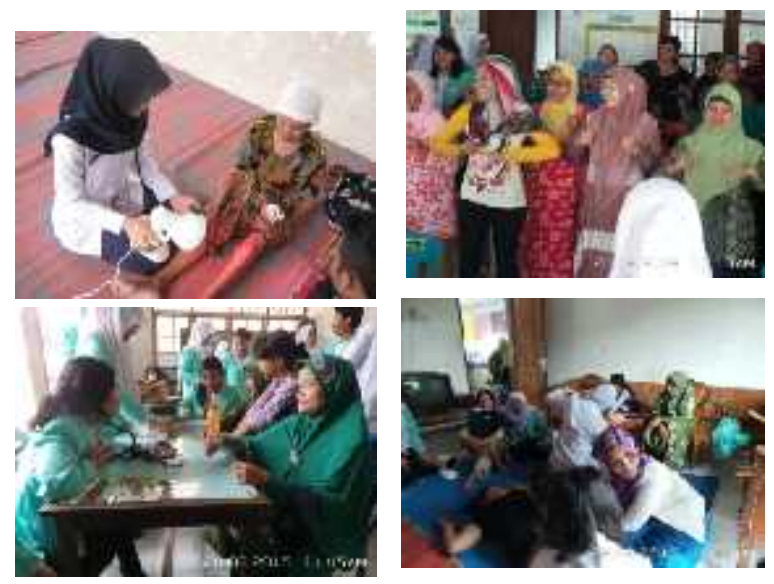

Gambar 5. Tim melakukan tindakan fisioterapi yang dilakukan kepada lansia

\section{HASIL DAN PEMBAHASAN}

Dari dari hasil kesepakatan dengan mitra di Desa Hamparan Perak. Pelaksanaan pengabdian yang dilakukan tim mengasilkan yang sangat bermanfaat terhadap lansia,posyandu dan Desa Hamparan perak sebagai berikut:

1. Terjadi peningkatan kesadaran lansia dan keluarga lansia dalam memeriksakan kesehatannya setiap bulannya ke posyandu

2. Jika dilakukan secara terus menerus akan terjadi penurunan kasus-kasus yang dialami oleh lansia. Setidaknya kegitan pengabdian ini dapat dilakukan 3 kali dalam setahun. 
3. Terjadi perbaikan Sarana dan prasarana terjadi kesepakatan anatara tim pengabdian dengan kelompok posyandu dan kepala desa tentang tempat posyandu akan diperbaiki unutk menunjang kegiatan posyandu setiap bulannya

4. Pemberian sinar infra red sangat diminati oleh lansia dikarenakan manfaat sinar infra red dianggap ampuh, dimana dapat langsung dirasakan manfaatnya.

\section{KESIMPULAN}

Setelah selesai melaksanakan pengabdian di Desa Hamparan Perak Kecamatan Hamparan Perak dapat disimpulkan sebagai berikut :

1. Pengelolaan posyandu lansia perlu ditangani lebih komprehensip meliputi sarana dan prasarana, kader dan dukungan para tokoh masyarakat di desa tersebut.

2. Pemberian sinar infra red untuk lansia yang mengalami gejala stroke dan stroke serta gangguan fisik lainnya sangat efektif karena manfaatnya langsung dapat dirasakan oleh lansia.

\section{UCAPAN TERIMAKASIH}

\section{Tim Pengabdian Kepada} Masyarakat mengucapkan banyak terimakasih kepada Stikes Siti Hajar Melalui LPPM, berkat bantuan dana dan kepercayaan yang di berikan, tim dapat melaksanakan dengan baik.. Tim Juga mengucapkan terimakasih kepada mitra khususnya kelompok posyandu dan Kepala Desa Hamparan PerakKabupaten Deli Serdang yang terus mendukung kegiatan pengabdian sampai selesai.

\section{DAFTAR PUSTAKA}

Aliah A, Kuswara F.F, Limoa RA, Wuysang. 2003. Gangguan Peredaran Darah Otak. Dalam: Kapita Selekta Neurologi.
Gadjah Mada University Press, Yogyakarta

Gofir, Abdul. 2009. Evidence Base Medicine ; Manajemen Stroke. Pustaka Cendekia Press. Yogyakarta

Maryam S. Asuhan Keperawatan pada Lansia, Jakarta: Trans Info Media; 2012.

Rosidawati. Mengenal Usia Lanjut dan Perawatanya, Jakarta: Salemba; 2008

Akmadi ; 2008 ; Pengertian Lansia dan Permasalahan Lanjut Usia; Diakses

tanggal 18/8/2018 dari http://lpkeperawatan.blogspot.co $\mathrm{m} / 2018 / 08 /$ lanjutusialansia.html.

Muttaqin, Arif, 2008, Buku Ajar Asuhan Keperawatan Klien dengan Gangguan Sistem Persarafan, Jakarta: Salemba Medika 